\title{
Moisture dynamics of WPC and the impact on fungal testing
}

Nele Defoirdt*, Soetkin Gardin, Jan Van den Bulcke, Joris Van Acker

Laboratory of Wood Technology, Ghent University, Coupure Links 653, 9000 Ghent, Belgium

Corresponding author: *Nele Defoirdt,

Laboratory of Wood Technology, Coupure Links 653, 9000 Ghent

Nele.defoirdt@UGent.be

Tel: +3292646123

Fax: +3292646233

\begin{abstract}
Wood-plastic composites (WPCs) are increasingly used in decking applications, where exterior exposure can lead to sufficient moisture for fungal deterioration. Standard tests recommended to assess fungal durability of WPC, but initially developed for wood or woodbased panels, are not applied in this study because the similarity in moisture behaviour for wood (-based panels) and WPC is questioned. The moisture dynamics of commercialised WPC versus wood-based panels were studied employing different moistening methods. The moisture sorption differences between various WPCs were minimal despite different wood contents, particle sizes, and plastics employed, but given sufficient time WPC wood particles gained sufficient water for fungal decay. To assay fungal durability of WPCs, immersion of the specimens for at least 1 week in water at $70^{\circ} \mathrm{C}$ seems to be the most effective pretreatment.
\end{abstract}

Keywords:

Wood-polymer composite

Wood-plastic composite

Moisture behaviour

Dimensional stability

Fungal testing 


\section{Introduction}

Wood-plastic or wood-polymer composites, known as WPCs, are a combination of wood and thermoset or thermoplastic polymers (Ellis, 2000; Clemons, 2002). Bringing those two materials together moderates their weaknesses. Compared to wood, WPC products are less susceptible to moisture sorption, easier to design, and need less maintenance, while compared to plastic the material becomes stiffer, cheaper, and lighter, and shows a lower thermal deformation by incorporation of wood. On the other hand, by mixing both materials, new frailties are introduced in the resulting material. Compared to wood, WPCs have a lower E-modulus and a higher density, and are more expensive. Finally, a WPC component is an anisotropic material that is more brittle than plastic and susceptible to colour change and moisture uptake (English and Falk, 1996; Clemons, 2002; Van Acker, 2006).

An increasing amount of WPC material is used as decking because it has a relatively stable colour and no need for chemical treatment against microbial attack or attack by termites. It is, furthermore, easy to install, nail, screw, and clean (stains are more easily removed) and does not splinter (Mankowski et al., 2005; Manning et al., 2006). Mankowski et al. (2005) and Manning et al. (2006) mentioned that warranties typically range from 10 to 25 years and some up to "limited lifetime.” Eder et al. (2007) remark that the perception of WPC products is totally different in Europe and America. In the U.S. and Canada, WPC is considered a cheap material made of recycled plastic and recycled wood and intended to replace preservative-treated wood. In Europe, WPC products are introduced to replace tropical hardwood as a high technological product made of renewable, but mostly virgin, resources for specific applications. Furthermore, in America most WPC boards are solid boards and $90 \%$ of the boards are based on HDPE, while in Europe more than $80 \%$ are hollow profiles and a considerable portion are PVC-based. Concluding, in Europe more expensive raw material is used to produce hollow profiles and prices vary from 0.5 to 1.5 times the prices for the best tropical hardwood decking (Crez and Jezequel, 2007), while in America cheaper but more raw material is used to make solid boards with prices that are nearly equal to those for the best tropical hardwood and 1.6-1.8 times the price of pressure-treated pine decking (Anonymous, 2004).

When WPC was introduced, wooden particles were thought to be entirely encapsulated and therefore inaccessible to water and fungi. These initial assumptions were later rejected (Morris and Cooper, 1998; Mankowski and Morrell, 2000; Mankowski et al., 2005; Manning et al., 2006). According to Klyosov (2007), WPC has to be regarded as a porous material, not only because the adhesion between wood and polymer might be poor and cause little gaps, but also since the polymer itself can be porous when it is filled with lignocellulose fibre and other additives at high temperature. In this case, plastic undergoes a rather noticeable degradation or depolymerisation, which leads to volatile organic compounds. Eventually, these VOCs, together with steam originating from the heating of residual moisture in the ligno-cellulosic fibres, can make the material foam resulting in a porosity that is poorly controllable. This porosity and the defective encapsulation results in small channels, which act as pathways for moisture, even to the core of the material.

Fungal tests recommended by the European Committee for Standardization to asses biological durability (CEN/TS 15534-1, 2006) are originally developed for application to wood or wood-based panels. As moisture is indispensable for fungal growth, this is only justified if WPCs and wood-based panels have similar moisture behaviour and if the test methods also put WPC in a worst-case scenario. A considerable amount of research has been reported concerning WPCs from well-defined laboratory-fabricated materials (Falk et al., 2000; Rangaraj and Smith, 2000; Pendleton et al., 2002; Verhey and Laks, 2002; Gnatowski, 2003; Clemons and Ibach, 2004). Yet WPC is a commercial product already available on the 
market as decking, siding, cladding, benches, etc. The research presented here studied first the moisture dynamics of a number of commercialized WPC decking products. As durability tests in the laboratory environment want to simulate a worst-case scenario of realistic in-service situations, this study searches for the situation with the largest impact. If WPC decking is installed with little or no ventilation, a moist environment can be created. Furthermore, bad installation can cause water traps on the deck and lead to immersion of parts of the boards, and leaving a wet fabric — for example, a doormat—on a WPC deck can cause moisture problems, as can ground contact applications.

After observing differences between the tested WPC products, a comparison with the moisture behaviour of wood-based panels is made.

\section{Materials and methods}

In order to incorporate the industrial manufacturing process and the diversity and inherent variability in product characteristics, commercialized WPC types were tested. For this research nine WPC decking products available on the Belgian market were used (coded from A to I); they varied in board type (solid or hollow profile), polymer (PVC, PE, PP), and wood content (50 to 70\%). The product properties are listed in Table 1. Materials B and C are produced by the same manufacturer but differ in colour. Materials F and $\mathrm{G}$ are the same product, but commercialised with another profile.

Common chipboard, plywood, oriented strand board (OSB), and medium density fibreboard (MDF) samples of the same sizes, but with the original board thickness, were added to the tests, to facilitate comparison of the moisture dynamics of WPC with these materials.

\subsection{Characterization of the products}

Certain product properties are not available or only available as a rough estimate due to manufacturer secrecy. A simple method to accurately measure the wood or polymer content of WPC products is not yet available. Besides wood content, the particle size is reported to determine the degree of sorption and thickness swell (Ibach et al., 2001; Verhey and Laks, 2002). Because no particle sizes were available, they were measured as specified below.

Unfortunately, detailed information about additives such as UV stabilizers, plasticizers, pigments, anti-oxidants, and lubricants is not known, although these can have an influence on certain properties.

To determine the particle size, small cylindrical cores with a diameter of 3-4 mm were sampled from every WPC product and were scanned using X-ray equipment built at the Centre for X-ray Tomography at Ghent University (UGCT). With this imaging method, WPC volumes were reconstructed with a voxel size of approximately $7 \mathrm{~mm}$. A 3-D image analysis approach was developed in order to segment wood and polymer and semi-automatically compute the characteristics of the WPC products. Briefly, this included the loading of the reconstructed slices in MATLAB ${ }^{\circledR}$, pre-processing of the data by filtering, and morphological cleaning and segmentation of the wood and polymer. Labelling of the particles could then be performed and is illustrated for WPC type B. However, proper segmentation relies on a sufficient X-ray density difference between wood and polymer, and as the distinction between wood and polymer is not always clear, automatic measuring of the wooden particles was not possible for all WPC types. Therefore only the largest particles were measured on crosssectional X-ray slices to get an impression of the size of the particles. For materials I and D, the CT scans were unclear and additional information was needed using a light microscope. It 
was assured that information from CT scans could also be estimated using microscopic images. For every product four images were analysed.

\subsection{Measuring moisture behaviour}

For the tests concerning moisture uptake and dimensional stability, test pieces of $50 \mathrm{x}$ $50 \times 5 \mathrm{~mm}$ were used with three replicates for each product, except for tests in the dynamic vapour sorption (DVS) device requiring cubes of $5 \times 5 \times 5 \mathrm{~mm}$ with only one replicate for each analysis. For product A the thickness was only $3.5 \mathrm{~mm}$, equalling the thickness of the hollow profile. Because the decking boards have a different pattern on top and bottom, samples from both sides were evaluated. Planed samples were also tested to eliminate the influence of the design at the surface.

Measured thickness swell and mass change were always calculated based on mass and thickness of the whole specimen. Finally the coefficient of dimensional change (\%) was calculated as:

$$
\frac{\text { final thickness swell }}{\text { final mass change }}
$$

\subsubsection{Impact of relative humidity}

With dynamic vapour sorption (DVS) it is possible to measure very accurately mass changes caused by (de)sorption of samples in varying humidity conditions. Cubes (side $5 \mathrm{~mm}$ ) went through a cycle of three stages while the temperature was fixed at $25^{\circ} \mathrm{C}$. In the first stage, the relative humidity was $0 \%$ until mass decrease was less than $0.002 \mathrm{~g} \mathrm{~s}^{-1}$ or with a total maximum time of 4 hours. Subsequently the RH was raised by $10 \%$ every hour up to $90 \%$ and then lowered using the same steps. In the last stage the RH was $0 \%$ for 4 hours. Every minute during this cycle, mass change was recorded. The device used was a DVS Advantage 1 Model from Surface Measurement Systems Ltd UK.

\subsubsection{Steam treatment}

Samples were steam treated in an autoclave at $120^{\circ} \mathrm{C}$ and 1 bar for 20 minutes. The specimens were put in inert receivers on a stainless steel grid at approximately $2 \mathrm{~cm}$ height to prevent any contact with occasionally present liquid water. Every two specimens were separated by two stainless steel grids. Before and after this treatment the thickness and mass were measured.

\subsubsection{Contact with a humid material in a damp environment}

To combine a hot and moist environment and contact with a wet object, specimens were wrapped in a wet bath towel and put in a closed plastic bag. The bag was put in an oven at $70^{\circ} \mathrm{C}$ for two weeks, while water was added to keep the material wet. Thickness and mass of the samples were measured before and after the treatment.

\subsubsection{Immersion in water at ambient temperature and in hot water}

Specimens, separated from each other and the bottom by stainless steel grids, were put in a receiver filled with demineralised water at room temperature. The thickness and mass were measured after $1,2,3,7,14$, and 21 days to get a sorption curve for each material. A parallel, closed set-up was put in an oven at $70^{\circ} \mathrm{C}$ and evaluated similarly. 


\subsubsection{Ultrasonic hot water bath}

In ultrasonic baths little shock waves have a brushing effect on the immersed object and are known as cleaning devices for laboratory material. For evaluating this effect on WPC, specimens were put randomly and separated from each other with stainless steel grids in an ultrasonic cleaning device filled with demineralised water. A frequency of $40 \mathrm{kHz}$ was used in two stages. In the first stage the water temperature was raised to $90^{\circ} \mathrm{C}$ over 90 minutes, and in the second stage the temperature stayed at $90^{\circ} \mathrm{C}$ for 90 minutes. Samples were then removed and cooled down, and thickness and mass were determined.

Due to a shortage of material I, this product was not included in the steam treatment and the immersion in the ultrasonic hot water bath.

Mutual comparison of the WPC materials was done by Wilcoxon rank-sum tests. The results are always shown as lines connecting the products that are not significantly different from each other.

\section{Results}

\subsection{Characterization of the products}

Figure 1a is a 3-D rendered volume of WPC product B, and its labelled equivalent is shown in Fig. 1b. The inset in Fig. 1a is an example of a cross-sectional slice and illustrates the presence of voids between particle and wood, possibly influencing the behaviour of the WPC material. Although good results are obtained for some of the WPCs, for others segmentation was extremely difficult with automated processing, and manual measurements were performed. Nevertheless, the efforts to determine wood particle characteristics continue, as valuable 3-D information can be derived from them.

In Table 2 the mean, standard deviation, minimum, median, and maximum area values of the ten largest wood particles are shown. It can be noticed that for some products the standard deviation in terms of percentage of the ten largest particles is up to $90 \%$. As can be seen macroscopically, there is a significant difference in the size of the particles that were used in the WPC products: The largest particles vary from $0.05 \mathrm{~mm}^{2}$ to $0.47 \mathrm{~mm}^{2}$. Material D has significantly larger particles than all other products, while I has considerably smaller particles, although the difference with material $\mathrm{A}$ is minor. The fact that the PP material, with the highest wood content, has the largest particles and the PVC composites, with the lowest wood content, have the smallest, has as result that sorption data can't be explained by only one of the factors being polymer, wood content, or particle size. Most likely a combination of these factors influences the moisture behaviour, but clear sorptionmaterial links can't be unravelled using only commercialized WPC products as certain factor combinations are not available.

Materials B, C, and F are not significantly different from each other and this is also the case for materials $\mathrm{C}$ and $\mathrm{H}, \mathrm{G}$ and $\mathrm{H}$, and $\mathrm{E}$ and $\mathrm{G}$. Although products $\mathrm{F}$ and $\mathrm{G}$ should be the same product according to the producer, material $G$ has smaller particles than material $F$.

\subsection{Moisture behaviour}

Flaking occurs in all tests, except for the DVS experiment. Although this involves very small quantities, it can affect the mass and thickness measurements. Only the PP product does not flake at all. Furthermore, these sorption tests induce a colour change. It seems likely that the superficial wood particles are the cause, which also explains why the planed surfaces show a rather significant colour change. 
The standard deviation of the thickness swell is larger than the standard deviation of the mass change because it is difficult to measure the thickness each time on exactly the same spot. Differences in results between samples of the top and the bottom of the decking board and between planed and original surface specimens are in most cases minimal and are therefore discussed altogether.

\subsubsection{Impact of relative humidity}

Figure 2 shows the moisture content during a cycle of varying relative humidity, and in Fig. 3 the maximum mass change is shown. WPC samples have a maximum moisture uptake between 0.5 and 3.4\%, which is significantly lower than the tested wood-based panel products with maxima between $8.9 \%$ for chipboard and up to $13.7 \%$ for plywood. The WPC product based on PP has a high wood content and relatively large particles and shows the highest moisture uptake. The PVC composites with only 50\% wood and relatively small particles exhibit the lowest moisture uptake. Materials B and C, made by the same producer and different only in colour, show, however, a significant difference in moisture behaviour. At the end of the first steps of the increased relative humidity, the specimens nearly reach equilibrium moisture content, but the moisture uptake is too slow to follow the further increasing relative humidity steps. This slow uptake continues even when relative humidity is already decreasing. However, at the beginning of the first decreasing step, a small drop is visible, probably because the surface did reach equilibrium at $90 \% \mathrm{RH}$ and gives moisture quickly to the drying air. Meanwhile the core material is still accumulating moisture on its way to equilibrium with the humidity. In this way the samples are still absorbing to equilibrate their moisture gradient after the short moisture descent.

\subsubsection{Steam treatment}

Mass and thickness changes are displayed in Fig. 3. There is no significant difference between the materials that can be explained by their specific properties. The mean mass change of WPC is $0.97 \%$, which is 6 to 23 times less than the reference materials, but a mean variance of $45 \%$ has to be noted. The mean thickness swell of the WPC samples is $5.2 \%$, whereas the swell of chipboard, MDF, and OSB is, respectively, 2, 7, and 9 times higher. The thickness swell of plywood is only half that of the WPC samples. Again the mean variance in terms of percentage of the WPC results is high, namely $31 \%$.

\subsubsection{Contact with a humid material in a damp environment}

The mass change of WPC (Fig. 3) for this test varies from 13.3 to $18.3 \%$ while the variances in terms of percentage on the measurements are relatively small (on average 14\%) and the reference materials reach values six to nine times higher. The thickness swell of the WPC varies from 4.5 to $15.1 \%$, with variances in terms of percentage of 8 to $179 \%$. Again the thickness swell of plywood is smaller than the mean value for the WPC material, while that of chipboard, OSB, and MDF is, respectively, 3, 6, and 8 times higher. Similarities and differences of the products can't be explained by the product properties.

\subsubsection{Immersion in water at ambient temperature and hot water}

After 21 days immersion in water at ambient temperature the mean mass change of the WPC materials is $10.7 \pm 3.7 \%$, while that of the samples immersed in water at $70^{\circ} \mathrm{C}$ is $18.6 \pm$ $2.7 \%$ (Fig. 3). This is on average, respectively, 10 (ambient temperature) and $11\left(70^{\circ} \mathrm{C}\right)$ times less than the mass change of the reference materials. The mean thickness swell at ambient temperature is $9.4 \pm 2.8 \%$ and $18.1 \pm 3.4 \%$ at $70^{\circ} \mathrm{C}$ (Fig. 3). The reference materials swell three to nine times more, except for the plywood, which has a smaller swell. 
Mass change and thickness swell curves (Fig. 4) of the samples immersed in water at ambient temperature show a distinctly higher sorption of material D. On average a quarter of the mass change of WPC after 21 days is caused by sorption in the first $24 \mathrm{~h}$, and in the same period $32 \%$ of the final thickness swell was induced. In hot water the moisture uptake and thickness swell are faster. After one day and two days, respectively, $46 \%$ and two thirds of the final mass change is reached. Concerning thickness swell, after one and two days, respectively, 51 and $73 \%$ of the final value is reached. Furthermore, after 21 days in hot water the samples seem to approach their equilibrium moisture content.

\subsubsection{Ultrasonic hot water bath}

The mean mass change in an ultrasonic hot water bath (Fig. 3) is $6.3 \pm 3.4 \%$, while that of the reference materials is up to 83 times higher in the case of MDF. The mean thickness swell varies from 4.5 to $16.8 \%$, while the swell for the reference materials goes from 5.2 up to $268.5 \%$ (Fig. 3). For a reason still unclear, product $\mathrm{H}$ shows a distinctively higher moisture uptake.

The mean coefficient of dimensional change caused by the different moistening methods is shown in Fig. 5. In most cases the coefficient is smaller for the reference materials and the steam treatment seems to be inversely proportional to the results of the other moistening methods.

\section{Discussion}

In this research the amount of sorption depends on the moistening method that is used. In the literature most data concern immersion of WPC in water at room temperature. Klyosov (2007) reports that WPC materials typically absorb 0.7 to $2 \%$ after $24 \mathrm{~h}, 1-5 \%$ after a week, and up to $18-22 \%$ after several months, but the results in this study indicate higher sorption after a day and a week. This discrepancy is explained by the difference in sample shape, more precisely the surface-to-volume ratio that affects the absorption rate (Mankowski et al., 2005; Morrell, 2007). While the figures of Klyosov (2007) concern the entire profiles of the boards, this study is based on 5-mm-thick slices of the boards that are able to reach a uniform moisture distribution sooner than thicker profiles do. Furthermore, by using the same dimensions for all WPC products, board shape does not influence the mutual comparison.

One of the consequences of sorption is thickness swell, which also depends on the moistening method used. In general the mean coefficient of dimensional change of plywood is 33 times smaller than the mean value of WPC material, which is three times the mean coefficient of the other reference materials. The mean coefficient of dimensional change of wood (within a range of moisture content of 6-14\%) is 0.15 (Forest Products Laboratory, 1999). Although the moistening method to assess this value is not mentioned, it should be noticed that the coefficient is smaller than that of WPC materials. A possible explanation for the high coefficients for the steam-treated specimens is probably moisture, present in the samples, that is converted into steam and leads to swelling. With all other treatments the thickness swell is most probably caused by external moisture. Finally, statistical evaluation of the coefficients shows that WPCs based on PVC frequently have higher coefficients than the other WPCs.

The comparison of the tested WPC materials leads to different rankings depending on the moistening method (Table 3). For example, material A has nearly the lowest mass change in the DVS analysis and during the immersion in water at ambient temperature, but the results of all other tests indicate that it belongs to the materials with the highest sorption. Because the latter methods include elevated temperatures, this could be the factor that influences the sorption of this PVC material. As PVC becomes weaker at high temperatures, the swell of the 
wood particles is moderated less. Concerning the PVC-containing materials, product A absorbs and swells more than product I, and as they both contain about $50 \%$ wood, the cause for this can only be linked to the larger particles of material A compared to I. Material D is always one of the most absorbent and swelling-prone materials when the moistening time is longer than a few hours.

Looking at the materials based on PE, all moistening methods, except for the steam treatment, cause relatively low mass change for material G. Because this product has a relatively high wood content, the lower results can be attributed to significantly smaller particles compared to materials $\mathrm{B}, \mathrm{C}$, and $\mathrm{F}$, all containing particles of nearly the same size. Because $\mathrm{B}$ and $\mathrm{C}$ are said to differ only in colour, the staining additive must be the source of the higher results for B. Finally, material $\mathrm{H}$, the PE-based product with the highest wood content but significantly smaller particles than materials B, C and F, is characterized by relatively high sorption and thickness swell.

In this study it is hard to explain the moisture behaviour by one product parameter only (polymer, wood content, particle size) because for example, the material based on PVC is also the one with the lowest wood content and the smallest particles. Apparently products with different compositions can manifest nearly the same moisture behaviour, as the difference in the results is relatively small.

Concerning practical use of this material, it is clear that in cases of high relative humidity only a small moisture sorption is expected without causing serious problems. However, if immersion lasts a few weeks, a considerable absorption (5 to over 20\%) and a thickness swell of at least 5\% is possible. Even when WPC material is in contact with a wet object for sufficient time, moisture sorption can become problematic. In addition to distortions, swelling, and buckling by water sorption, fungal growth can be initiated as well. The moisture level that is reached in the WPC material, as well as the time of wetness (Van den Bulcke and Van Acker, 2008) determine the occurrence of biological degradation. Concerning the first condition, wood is said to be susceptible to fungal growth if it has a moisture content above the fibre saturation point. Because polymers are considered to absorb either negligible small amounts of water or no water at all (Manning et al., 2006), this means a moisture content of $10 \%$ to $14 \%$ for composite materials with, respectively, 50 to $70 \%$ wood. According to the performed tests those levels of moisture content can be reached in immersed specimens, certainly in the top layers of the products. This is in accordance with Manning et al. (2006), warning that samples put outdoors were found to develop levels of moisture in the outer portions of the material that are sufficient to initiate and support fungal decay.

This research proves that WPC materials and wood-based panel products have significantly different moisture behaviour; i.e., moisture absorption is much slower for WPCs. Practically, this means that WPC samples cannot reach a sufficiently high moisture level during short-term testing as described in the standards developed for wood or wood-based panels. As they do reach a sufficiently high moisture level in the performed tests, one could consider those standard test methodologies as a bad simulation of the worst-case scenario for WPC. Therefore a test methodology specifically for these composite materials is required, or the standards for wood and wood-based panels can be adapted by an appropriate preconditioning step aiming at a high moisture level in the material in the shortest time possible. The thickness swell in itself is less important, although it can create channels for water and fungal hyphae to penetrate the test specimens.

The preconditioning step in fungal testing can be based on the moistening methods in this study. The methods differed in temperature $\left(20^{\circ} \mathrm{C}\right.$ to $\left.120^{\circ} \mathrm{C}\right)$, duration (20 minutes to three weeks), and the way moisture is provided (vapour/steam, a moist object, or water). Concerning the immersion, a higher temperature makes the sorption faster. By contrast, Wang and Morrell (2004) suggested that, after immersing WPC products in water at $5^{\circ} \mathrm{C}$ and $25^{\circ} \mathrm{C}$, 
the practical impact of elevated temperature on the moisture uptake is limited. Of course $70^{\circ} \mathrm{C}$ is rarely reached in nature, but in lab tests it is just a way to pass faster through the sorption curve. Yet temperature is not the dominating factor. When moist air is used, the results of the steam treatment $\left(120^{\circ} \mathrm{C}\right)$ are a lot smaller than the maximum sorption at DVS analysis $\left(25^{\circ} \mathrm{C}\right)$, which means that the specimen size and/or duration (resp. 20 minutes vs. ca. 13 hours) determined likewise the sorption of the material. Van Acker (2006) also describes time as an important factor in the moistening process and suggests that this could be a critical factor in the service life of WPC. When comparing the maximum sorption in DVS analysis and that after one day of immersion in water at ambient temperature, immersion turned out to be a more intensive moistening method than putting the samples in an environment with high relative humidity. Immersing samples for 14 days in water at $70^{\circ} \mathrm{C}$ yields one fifth more sorption than bringing them in contact with a wet towel in a moist environment at $70^{\circ} \mathrm{C}$. Finally, putting ultrasonic vibrations through the water can raise the sorption only in a limited way. In conclusion, immersing the materials in hot water for at least one week seems to be the most effective and simple way to moisten samples as pre-treatment for fungal tests.

Concerning the time of wetness, it is important that the specimens stay wet during the fungal tests.

\section{Conclusions}

Assessing biological durability of WPC using tests that were developed for wood or wood-based panels is only justified if their moisture behaviour is similar and if the test methods also put WPC in a worst-case scenario. Therefore the moisture dynamics of commercialised WPC materials and wood-based panels was assessed by performing different moistening methods.

The mutual comparison of the WPC materials shows that in spite of the differences in composition (e.g., polymer, wood content, wood particle size) a similar moisture level is attained. After immersion in hot water the most severe effects are measured: on average $19 \pm$ $3 \%$ mass change and $18 \pm 3 \%$ thickness swell. The moisture levels of the wooden particles range with this method from 21 to $43 \%$, enabling initiation of fungal growth.

The comparison of the results with those for wood-based panels reveals a significant difference in moisture behaviour. As WPC absorbs less, and more slowly, and there is a smaller amount of thickness swell (except for plywood), biological durability must be assessed by using tests that take the slow sorption into account. The existing standard for wood-based panels could be adapted by including a pre-treatment that brings WPC to a high moisture level at the start of the fungal test. Concerning the moistening methods in this research, an immersion in water at $70^{\circ} \mathrm{C}$ for at least one week seems to be the simplest and most effective method.

\section{Acknowledgements}

We wish to thank Plastivan nv, Tech-Wood Nederland bv, Deceuninck nv, Opti-wood bvba/sprl, eco-Profil nv, Neofibra nv, and timber yards Hoebeek and Vercruysse for supplying the WPC boards. Furthermore, we want to express our gratitude to the Centre for X-ray Tomography at Ghent University (UGCT) for the CT scans and the Fund for Scientific Research-Flanders (FWO Belgium) for the postdoctoral funding granted to Jan Van den Bulcke. 


\section{References}

- Anonymous, 2004. Decking: serious alternatives.(Home: your backyard). Consumer Reports, July. Consumers Union of the United States, Inc., Yonkers, New York.

- CEN/TS 15534-1, 2006. Wood-plastics composites (WPC) - part 1: Test methods for characterisation of WPC materials and products. European Committee for Standardization, Brussels.

- Clemons, C., 2002. Wood-plastic composites in the United States - the interfacing of two industries. Forest Products Journal 52, 10-18.

- Clemons, C.M., Ibach, R.E., 2004. Effects of processing method and moisture history on laboratory fungal resistance of wood-HDPE composites. Forest Products Journal 54, 5057.

- Crez, A.F., Jezequel, B., 2007. European wood composite decking market. In: Centre Technique du Bois et de l'Ameublement, (Ed.), Proceedings of 3rd Wood Fibre Polymer Composites International Symposium, Bordeaux.

- Eder, A., Weinfurter, S., Schwarzbauwer, P., Strobl, S., 2007. WPCs - an updated worldwide market overview including a short glance at final consumers. In: Centre Technique du Bois et de l'Ameublement, (Ed.), Proceedings of 3rd Wood Fibre Polymer Composites International Symposium, Bordeaux.

- Ellis, W.D., 2000. Wood-polymer composites: Review of processes and properties. Molecular Crystals and Liquid Crystals 353, 75-84.

- English, B.W., Falk, R.H., 1996. Factors that affect the application of woodfiber-plastic composites. In: Forest Products Society, (Ed.), Woodfiber-plastic composites: Virgin and recycled wood fiber and polymers for composites. Forest Products Society, Madison, WI, pp 189-194.

- Falk, R.H., Lundin, T., Felton, C., 2000. The effects of weathering on wood-thermoplastic composites intended for outdoor applications. In: Forest Products Society, (Ed.),

Proceedings of the $2^{\text {nd }}$ Annual Conference on Durability and Disaster Mitigation in WoodFrame Housing, Madison, WI, pp 175-179.

- Forest Products Laboratory, 1999. Wood handbook - Wood as an engineering material. U.S. Department of Agriculutre, Forest Service, Forest Products Laboratory, Madison, WI.

- Gnatowski, M., 2003. Water absorption by wood plastic composites in exterior exposure. In: Forest Products society, (Ed.), Proceedings of the 8th International Woodfiber-Plastic Composites Conference, Madison, WI pp 249-256.

- Ibach, R.E., Rowell, R.M., Lange, S.E., Schumann, R.L., 2001. Effects of wet-dry cycling on the decay properties of aspen fiber high-density polypropylene composites. In: Forest Products Society, (Ed.), Proceedings of the 6th International Conference on WoodfiberPlastic Composites, Madison, WI, pp 267-270.

- Klyosov, A.A., 2007. Wood-plastic composites. John Wiley \& Sons, Inc., Hoboken.

- Mankowski, M., Morrell, J.J., 2000. Patterns of fungal attack in wood-plastic composites following exposure in a soil block test. Wood and Fiber Science 32, 340-345.

- Mankowski, M.E., Ascherl, F.M., Manning, M.J., 2005. Durability of wood plastic composites relative to natural weathering and preservative treatment with zinc borate. IRG/WP/05-40316. The International Research Group on Wood Protection, Stockholm.

- Manning, M.J., Ascherl, F.M., Mankowski, M.E., 2006. Wood-plastic composites and the durability dilemma: Observations from the field. IRG/WP/06-40351. The International Research Group on Wood Protection, Stockholm. 
- Morrell, J.J., 2007. Durability of wood plastic composites: Where we've been and how we can get better. In: Centre Technique du Bois et de l'Ameublement, (Ed.), Proceedings of the 3rd Wood Fibre Polymer Composites International Symposium, Bordeaux.

- Morris, P.I., Cooper, P., 1998. Recycled plastic/wood composite lumber attacked by fungi. Forest Products Journal 48, 86-88.

- Rangaraj, S.V.,Smith, L.V., 2000. Effects of moisture on the durability of a wood/thermoplastic composite. Journal of Thermoplastic Composite Materials 13, 140161.

- Pendleton, D.E., Hoffard, T.A., Adcock, T., Woodward, B., Wolcott, M.P., 2002. Durability of an extruded HDPE/wood composite. Forest Products Journal 52, 21-27.

- Van Acker, J., 2006. Testing biological durability of wood-plastic composites. IRG/WP/06-20347. The International Research Group on Wood Protection, Stockholm.

- Van den Bulcke, J., Van Acker J., 2008. Time resolved analysis of the moisture dynamics of plywood. COST Action E37: Sustainability through new technologies for enhanced wood durability, Bordeaux, pp 65-75.

- Verhey, S.A., Laks, P.E., 2002. Wood particle size affects the decay resistance of woodfiber/thermoplastic composites. Forest Products Journal 52, 78-81.

- Wang, W.H., Morrell, J.J., 2004. Water sorption characteristics of two wood-plastic composites. Forest Products Journal 54, 209-212. 
Fig. 1. (a) Original scan of WPC type B with insertion of a cross-sectional slice, and (b) image of the labelled wood particles. Scale bar $=1 \mathrm{~mm}$.
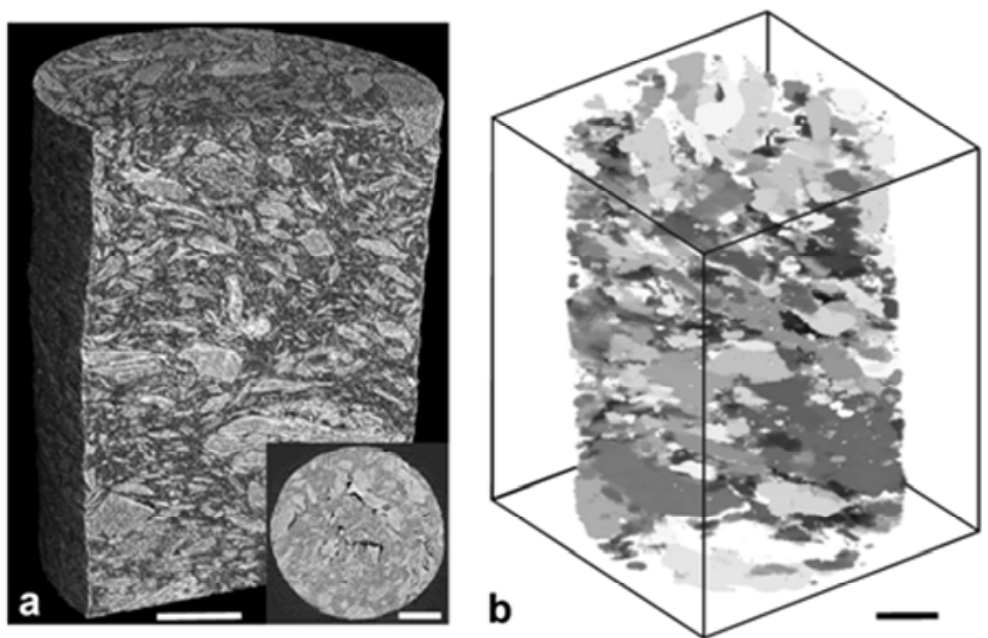

Fig. 2. Sorption curves during DVS analysis of (a) WPC, and (b) comparison with the reference materials.

Fig. 3. Mass change and thickness swell caused by sorption through different moistening methods (no values for steam treatment and ultrasonic hot bath treatment of material I).
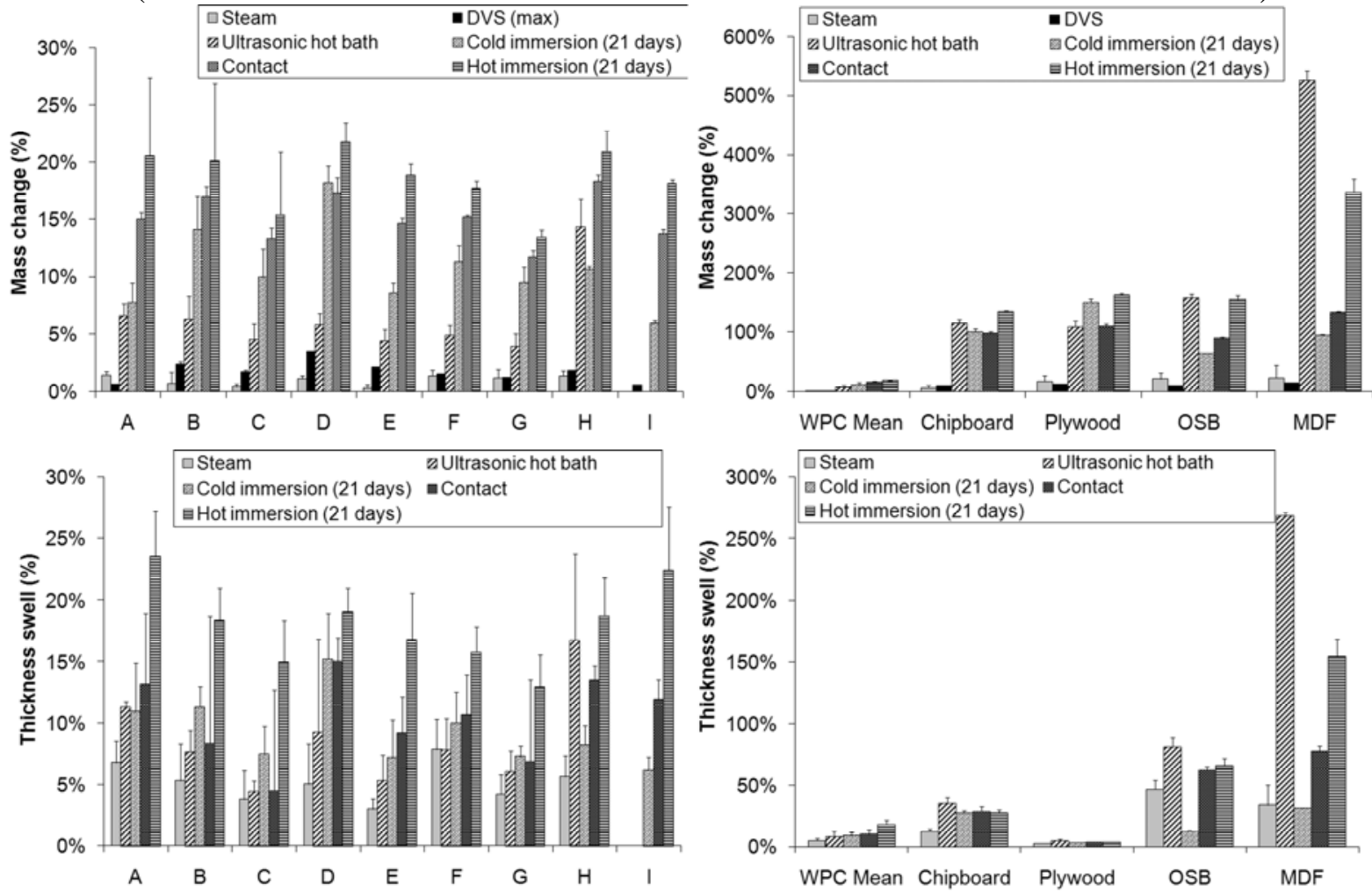
Fig. 4. Sorption curves and thickness swell curves caused by immersing WPC in water at ambient temperature and at $70^{\circ} \mathrm{C}$.
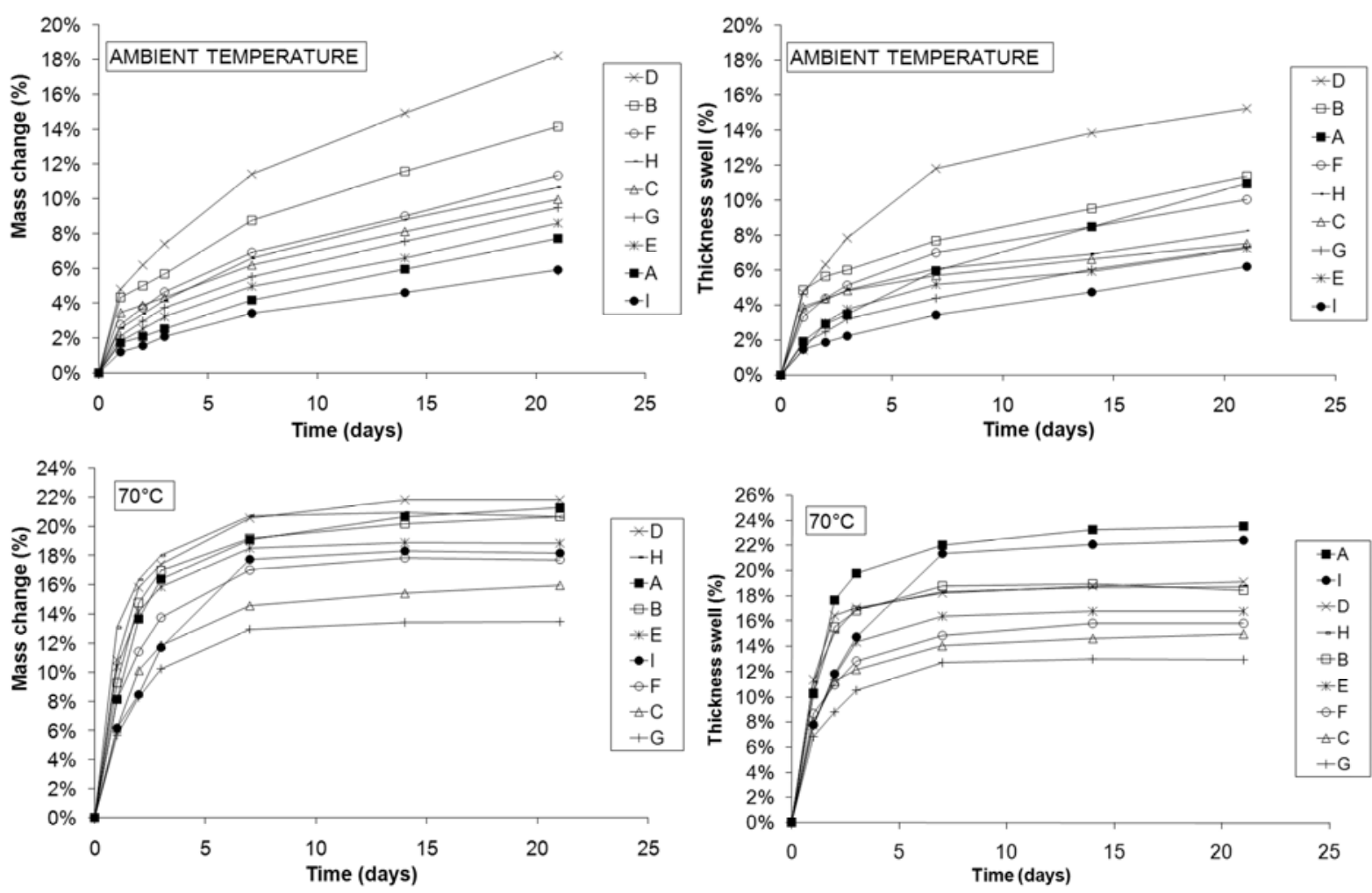

Fig. 5. Coefficient of dimensional change through different moistening methods.

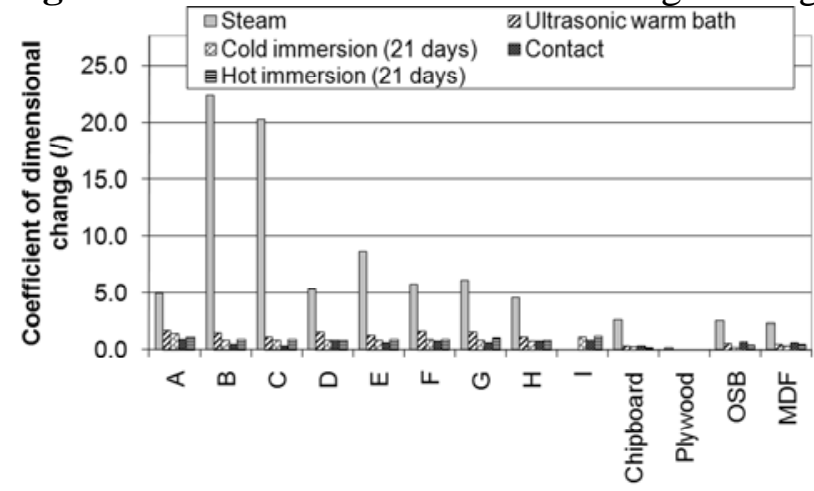




\section{Table 1}

General product properties of the tested materials, as provided by the producers

\begin{tabular}{llll}
\hline Code & Board type & Polymer & Wood content (\%) \\
\hline A & Hollow & PVC & 50 (softwood) \\
B & Solid & PE & $50-60$ (recycled wood) \\
C & Solid & PE & $50-60$ (recycled wood) \\
D & Hollow & PP & 70 (softwood) \\
E & Hollow & PE & 55 (softwood) \\
F & Hollow & PE & $60-70$ \\
G & Hollow & PE & $60-70$ \\
H & Solid & PE & 70 \\
I & Hollow & PVC & 50 \\
\hline
\end{tabular}




\section{Table 2}

Mean area, standard deviation, minimum, median, and maximum area of the ten biggest wood particles

\begin{tabular}{lllllll}
\hline Product & $\begin{array}{l}\text { Mean area } \\
\left(\mathrm{mm}^{2}\right)\end{array}$ & $\begin{array}{l}\text { Standard deviation } \\
\left(\mathrm{mm}^{2}\right)\end{array}$ & $\begin{array}{l}\text { Minimum } \\
\left(\mathrm{mm}^{2}\right)\end{array}$ & $\begin{array}{c}\text { Median } \\
\left(\mathrm{mm}^{2}\right)\end{array}$ & $\begin{array}{l}\text { Maximum } \\
\left(\mathrm{mm}^{2}\right)\end{array}$ & $*$ \\
\hline D & 0.47 & 0.26 & 0.08 & 0.47 & 1.16 & $\mathrm{D}$ \\
F & 0.24 & 0.20 & 0.06 & 0.18 & 0.94 & $\mathrm{~F}$ \\
B & 0.23 & 0.21 & 0.07 & 0.16 & 0.95 & B \\
C & 0.19 & 0.12 & 0.07 & 0.15 & 0.59 & $\mathrm{C}$
\end{tabular}

* Lines connect materials that are not significantly different from each other according a Wilcoxon rank test 


\section{Table 3}

Ranking according a Wilcoxon rank-sum test: materials connected with a line are not significantly different from each other

\begin{tabular}{|c|c|c|c|c|c|c|}
\hline & & Steam & Ultrasonic & $\begin{array}{l}\text { Cold } \\
\text { imme }\end{array}$ & Contact & Hot immersion \\
\hline \multirow{9}{*}{$\begin{array}{l}\text { Mass } \\
\text { change }\end{array}$} & Less & $E$ & $\mathrm{G}$ & I & G & G \\
\hline & & $\mathrm{C}$ & $\mathrm{E}$ & $\mathrm{A}$ & C & $\mathrm{C}$ \\
\hline & & $\mathrm{B}$ & $\mathrm{C}$ & $\mathrm{E}$ & I & $\mathrm{F}$ \\
\hline & & $\mathrm{D}$ & $\mathrm{F}$ & $\mathrm{G}$ & $\mathrm{E}$ & I \\
\hline & & $\mathrm{G}$ & $\mathrm{D}$ & $\mathrm{C}$ & $\mathrm{A}$ & $\mathrm{E}$ \\
\hline & & $\mathrm{H}$ & B & $\mathrm{H}$ & $\mathrm{F}$ & B \\
\hline & & $\mathrm{F}$ & $\mathrm{A}$ & $\mathrm{F}$ & $\mathrm{B}$ & $\mathrm{H}$ \\
\hline & $\downarrow$ & $\mathrm{A}$ & $\mathrm{H}$ & B & $\mathrm{D}$ & $\mathrm{A}$ \\
\hline & \multicolumn{2}{|l|}{ More } & & $\mathrm{D}$ & $\mathrm{H}$ & $\mathrm{D}$ \\
\hline \multirow[t]{9}{*}{ Thickness } & Less & $\mathrm{E}$ & $\mathrm{C}$ & I & $\mathrm{C}$ & $\mathrm{G}$ \\
\hline & & $\mathrm{C}$ & $\mathrm{E}$ & $\mathrm{E}$ & $\mathrm{G}$ & C \\
\hline & & $\mathrm{G}$ & $\mathrm{D}$ & G & $\mathrm{E}$ & $\mathrm{F}$ \\
\hline & & $\mathrm{D}$ & G & C & $\mathrm{F}$ & $\mathrm{E}$ \\
\hline & & $\mathrm{H}$ & $\mathrm{F}$ & $\mathrm{H}$ & I & $\mathrm{H}$ \\
\hline & & B & B & $\mathrm{F}$ & B & $B$ \\
\hline & & $\mathrm{A}$ & $\mathrm{A}$ & $\mathrm{A}$ & $\mathrm{A}$ & $\mathrm{D}$ \\
\hline & $\downarrow$ & $\mathrm{F}$ & $\mathrm{H}$ & $\mathrm{B}$ & $\mathrm{H}$ & I \\
\hline & More & & & D & $\mathrm{D}$ & A \\
\hline
\end{tabular}

